\title{
Comparison of Elderly People's Perception of Homely Feeling towards Room Environment in Their Own Home and in Two Nursing Homes in Thailand
}

\author{
Ariya Atthawuttikul and Nopadon Sahachaisaeree
}

\begin{abstract}
They responded this study compared the elderly people's perception of the room environment in their own home with those in two nursing homes whether the environment conveyed a homely feeling to a different extent or not. The two nursing homes were Sawangkanivet nursing home and BanBangkae social welfare development center for older persons. The room environment in focus included the size and ceiling height of the room and the furniture and house ware arrangement. The sample group consisted of 60 elderly people, 30 from each nursing home, with an average age of 75 years. They responded to items in a questionnaire regarding the degree of their following feelings towards or evoked by the room environment general positive and negative feelings; feeling of privacy; and feeling of freedom. Their responses were analyzed statistically, by t-test and ANOVA, to compare the extent of the homely feeling they experienced in their own home with those in the two nursing homes. The results of the analysis indicated that, overall, the elderly people experienced significantly more homely feeling in their own home compared to what they experienced in the two nursing home. The findings from this study can be useful for designing better nursing home and new government policy on nursing home.
\end{abstract}

Index Terms-Perception of room environment, home, Nursing home, elderly people.

\section{INTRODUCTION}

Thailand's elderly population is increasing rapidly and is expected to reach 25 percent by 2020 to make Thailand a full-fledged aged society. The fact that the elderly are living longer with a larger proportion of elderly women than men, the worker-age population supporting the elderly is diminishing. Moreover, changing lifestyles in urban society will lead to risks and health problems, especially chronic diseases, because the elderly experience physical, mental, economic and social degeneration. The aforementioned population structure reflects of the importance and necessity of service improvements on health and society facilitating the elderly in being able to engage in self-care and live long, quality lives when the elderly have difficulty caring or are unable to care for themselves [1] (Siripanich, 2010) .

At present, public and private agencies have created many housing services such as developed housing projects, residences and condominiums in order to provide proper

Manuscript received November 13, 2015; revised February 20, 2016.

The authors are with the Department of Multidisciplinary Design Research, Faculty of Architecture, King Mongkut's Institute of Technology Ladkrabang, Thailand (e-mail: atthawuttikulariya@gmail.com, ksnopadon@gmail.com). accommodation for the elderly. [2] (Thamthamrong, 2007) However, although such optional residences for the elderly might respond to the physical needs of the elderly, the emotional factors of living in a new place with someone else who is not a relative or having to living in a different environment from their old homes and their backgrounds might cause them to encounter some problems and affect their physical and mental health. [3] (Chaluthat, 2008)

The present research was aimed at studying the physical factors creating home-like feelings in nursing homes for the elderly by studying nursing homes for the elderly with varying physical conditions in order to learn and compare perceptions on issues that communicate home-like feelings in the elderly at each facility. The researcher selected Sawangkaniwet Nursing Home and Banbangkhae Social Welfare Development Center for Older Persons as case studies for the present research because both facilities provide nursing home services to two groups of elderly with differences in many dimensions physically and environmentally, services for the elderly, living condition and characteristics of elderly living in the aforementioned nursing homes, which provides clear comparison of each of the aforementioned aspects.

\section{ENVIRONMENTAL PERCEPTION THEORY}

Environment can be summarily defined in two types, presentational meaning and responsive meaning as shown in Fig. 1. Environment was presented on two sides, namely presentational side, which communicates visible aspects, and representational side, which acts to communicate to facility users to understand the benefits of the utilization of such facilities, e.g., behaviors at the facility, and communication of the suitability of the facility, including its values. As for responsive meaning, it acts to lead to action, such as affective feelings, e.g., whether the facility is preferred or otherwise when first visited, evaluative, which communicates the degree of preference and prescriptive, which leads users to action, e.g., sitting in a chair that appears comfortable, etc. [4] (Hershberger et al., 1974)

A good environment design should communicate the meaning presented by the environment as well as responsive meaning. Different environments are all products of factors from previous experience among persons utilizing the environment and factors on the properties and objectives of the user of the facility. Therefore, a design research generally 
involves studies on responsive meaning processes in comparison with the qualities of facility users, and perception of facility users is an important part in studying the perception of behaviors that influence behaviors and environment according to the chart in Fig. 2. [5] (Sahachaiseree, 2003).

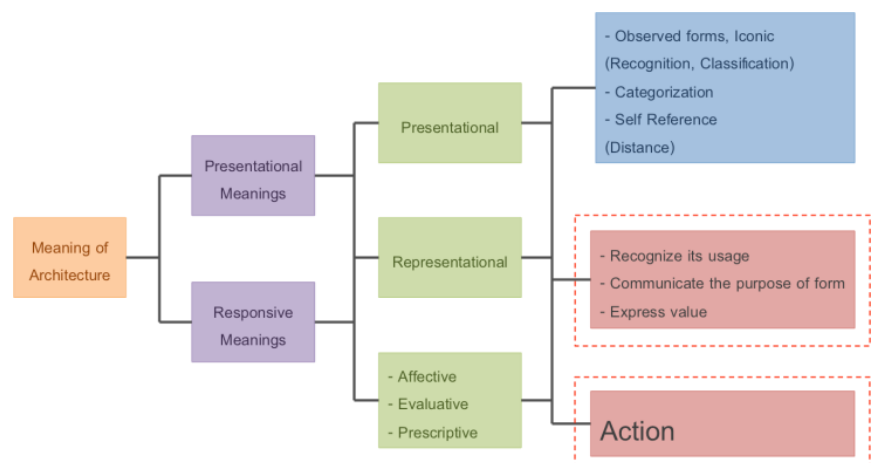

Fig. 1. Types of meaning in architecture.

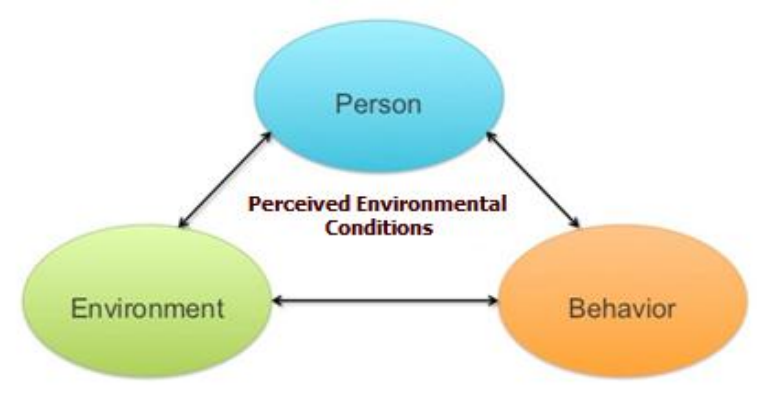

Fig. 2. Relationships between person, environment and behavior.

Factors influencing a sense of birthplace by affecting conscience were divided into two factors: personal factors and environmental factors. Architectural work affects behavior and alters the behaviors of the person along with the characteristics of the environment and affecting the mental state of the human being. The user of a building is considered a recipient of a message, that is to say, the user is the receiver of information expressed by the designer in architectural work. Humans can perceive and interpret surrounding environment and information through sensory organs. As in Fig. 2, each person can perceive differently, and so architectural work interpretation is different, whether in terms of emotions, aptitude, behavior, ability, attitude, needs, taste, or habit differences.[6] (Horayangkoon, 1998)

\section{PERCEPTION OF THE MEANING OF "Home"}

Communicating the meaning of home in tangible angles possibly mean boundaries put in place family members. The home serves to protect family members from the sun, wind and rain as well as serving to support activities happening in the home. In addition, homes come in different shapes and sizes. On another hand, however, homes are not the only areas of possession or venues for holding events but also have cultural, sociological, political and economical meanings. It might be said that a home is not only a "place" but is what can make people perceive the unique qualities of the inhabitants of the home. Three dimensions for the meaning of home are mentioned as follows:

\section{A. Cultural Dimensions}

Home reflects cultural and social values. These values are expressed in living characteristics and behaviors, e.g., race and lineage, and the roles of family members can be indicated from the arrangement of utilized areas inside the home.

\section{B. Socio-Demographic Dimensions}

Indicators about each relationship between the inhabitants of the same home include family structure, gender, age, religious beliefs, culture and tradition, all of which influence perceptions and use of home interior areas. For example, people with good status in a household tend to have their own person areas as a means of displaying their superior status over other household inhabitants, or elderly people who have similar daily routines every day as compared to younger family members do not like changes in their homes such as decorations or the use of furniture, etc.

\section{Psychological Dimensions}

The home serves to communicate the identity of the inhabitant to others, including fellow inhabitants. This might be expressed through decorations as a show of taste, unity of member groups, or reflection of self-esteem. Each dimension is made up of sub-factors as shown in Fig. 3. [7] (Lawrence, 1987)

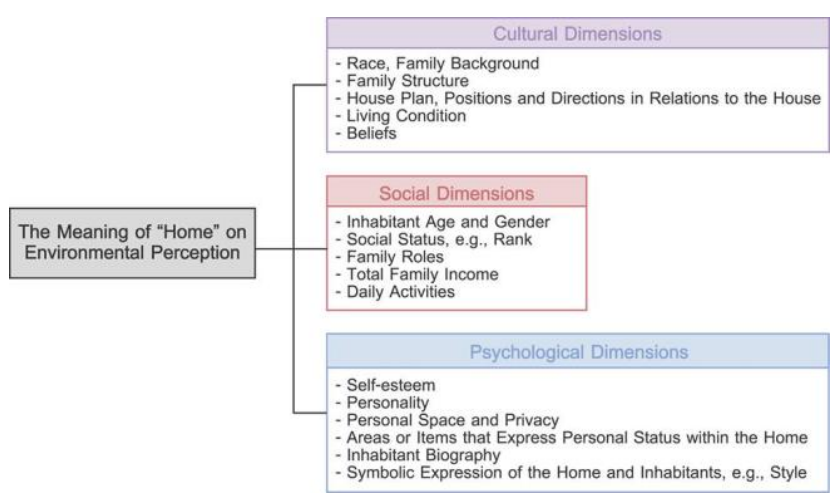

Fig. 3. Meaning of home in different dimensions.

Apart from the aforementioned dimensions, research on the perception of elderly on the meaning of home in elderly nursing homes. [8] (Marsden, 1999) had given importance to the aforementioned perception on the ability to control privacy and having a boundary under their control. Furthermore, the present research was focused on familiarity to new residences in comparison to original homes. The aforementioned familiarity was divided into three types: 1) feelings of warmth and safety, having an enclosed space with clear divisions between public and private sections, 2) physical ratio: relationship between the changed physical characteristics of the elderly due to age and the environment in order to perform normal daily activities and 3) naturalness of the surroundings.

\section{RESIDENCES OR HOMES FOR THE ELDERLY}

Nursing homes for the elderly are considered an important factor that affects the living conditions of the elderly, which 
will help provide the elderly with good emotional well-being and physical health. Shown in Fig. 4, these are Activity of Daily Living. Nursing homes for the elderly have to be designed to respond to the Activity of Daily Living (ADL) requirements of the elderly and provide a homely environment using six factors: 1) Privacy, 2), Dignity, 3) Choice, 4) Independence, 5) Individuality and 6) Homelike Surroundings. [4] (Hershberger et al, 1974)

Hershberger et al. (1974) [4] expanded on nursing homes for the elderly, asserting the need for living conveniences for the elderly in addition to the six factors by Wilson et al. (2002) [9] above such as in terms of uncomplicated directions and path finding, high degree of safety in accessing utility areas, which must be easily accessible, sight and familiarity with local lifestyle, attraction and arrangement of utility areas, so inhabitants can place and arrange personal belongings and suitable alterations of the environment to suit the individual personality of each inhabitant.

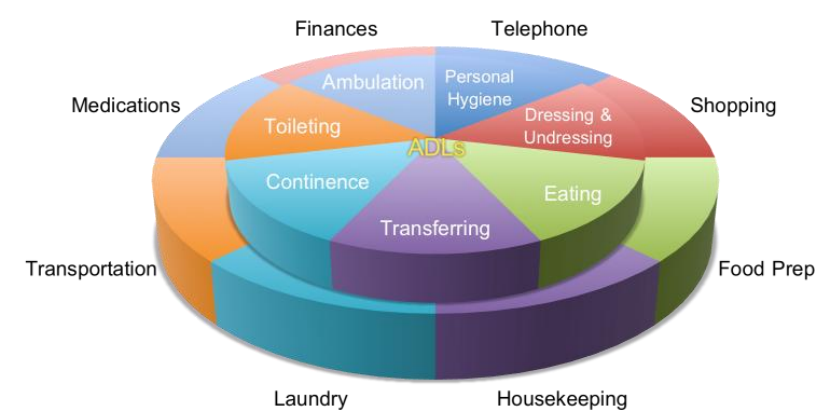

Fig. 4. Activity of daily living (ADL).

\section{ReseARCh Methodology}

The population and sample group for the this research was composed of 30 elderly residing at Sawangkaniwet Nursing Home for the Elderly and 30 elderly residing at Banbangkhae Social Development Welfare for Older Persons, making a total of 60 subjects. The researcher created the research instrumentation, which was divided into the following two parts: The Physical Characteristics Survey Form for the residences of the elderly in both of the two aforementioned facilities for studying the internal and external physical characteristics of Sawangkaniwet Building and Banbangkhae Social Welfare Development Center and the Elderly Opinion Level Assessment Questionnaire on living at the nursing homes divided into the following five parts: 1) demographic data of the sample group; 2) information on the original homes of the sample group; 3) opinion data on physical characteristics affection that communicated privacy; 4) opinion data on physical characteristics that affected positive thinking and 5) opinion data on independence from the interior environment of the nursing homes. Scoring ranged from 1 to 5 rating points. (Likert, 1967) [10] from Most Agree to Least Agree respectively. In addition, inquiries on other data are open-ended questions for in-depth data inquiries, e.g., why elderly moved to the nursing home, death of a family member or abandonment by family, etc.

\section{RESEARCH FINDING}

The present research found that, there are environmental conditions on physical characteristics and perception that communicated homeliness were found in that the interior environment of both nursing homes for the elderly, namely, Sawangkaniwet Nursing Home for the Elderly and Banbangkhae Social Welfare Development Center affected perception that communicated home-like feelings with no variances. The aforementioned finding might be due to the fact that the elderly had lived in the aforementioned nursing homes for a long period of time and some elderly had willingly moved to live in the nursing homes based on their own decisions. However, there were differences in the factors reflecting the background of the elderly, which were very significant. The present research found that are reinforcing factors for the elderly to feel that nursing homes and shelters for the elderly had perception of products conveying home-like feelings such as the fact that the elderly can choose furniture or furnishings to decorate their own rooms. In addition personal private space is provided for the elderly to perform some personal activities, and the fact that the elderly were living at the nursing homes or shelters willingly improved the perception of products that conveyed a sense of home. The aforementioned finding concurred with data obtained from Wilson et al. (2002) [9] that stated that nursing homes for the elderly are considered an important factor that affected the living conditions of the elderly, that will help the elderly have good mental and physical health, that designs are needed to accommodate daily living activities and create a home-like environment such as living privacy, dignity, choice, independence and individuality. In addition, the aforementioned concurred with the research by Lawrence (1987) [7] on perception of homeliness in cultural, social and psychological dimensions.

\section{REFERENCES}

[1] B. Siripanich, Annual Report on the Situation of Thai Elderly, Bangkok, Thailand: TQP Printing Press, 2010, pp. 9-25.

[2] K. Thamthamrong, "Architectural design for all," Journal of Architectural and Planning Research and Studies, vol. 1, no. 1, pp. 94-105, 2002.

[3] T. Charuthat, Environmental Design Manual for the Elderly and Persons of Every Age, Bangkok, Thailand: Chulalongkorn University Printing Press, 2008, ch. 2.

[4] R. Hershberger, Predicting the Meaning of Architecture, in Designing For Human Behavior: Architecture and the Behavioral Sciences, Stroudsburg, PA: Dowden, Hutchinson and Ross, 1974, pp. 147-156.

[5] N. Sahachaiseree, Behavior and Environment Teaching Materials, Bangkok, Thailand: Chulalongkorn University Printing Press, 2003, ch. 3.

[6] W. Horayangkoon, Human Behaviors and Environment: Behavioral Basis for Designs and Planning, Bangkok, Thailand: Chulalongkorn University Printing Press, 1998, ch. 5.

[7] R. J. Lawrence, "What makes a House a Home," Environmental and Behavior, vol. 19, no. 2, pp. 154-168, March 1987.

[8] J. P. Marsden, "Environmental and behavior," Older Persons' and Family Members' Perceptions of Homeyness in Assisted Living, vol. 31, no. 1, pp. 84-106, 1999.

[9] R. S. Wilson, L. A. Beckett, L. L. Barmes, J. A. Schneider, J. Bach, D. A. Evans, and D. A. Bennett, "Individual differences in rates of change in cognitive abilities of older persons," American Psychological Association, Psychology and Ageing, vol. 17, no. 2, pp. 179-193, June 2002.

[10] R. Likert, "The method of constructing and attitude scale," Reading in Attitude Theory and Measurement, M. Fishbeic, Ed. New York: Wiley \& Son, 1967, pp. 90-95. 


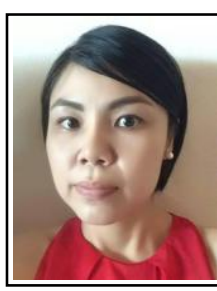

Ariya Atthawuttikul is doctoral researcher at King Mongkut's Institute of Technology Ladkrabang, Thailand. Her design practice and research areas are in product, packaging, and graphic design. Ariya's master degree research related to the suitable impact absorbent surface in the bathroom for elderly people at Banbangkhae Social Development Center 1, Bangkok This paper, drawn from her doctoral research, focused on the design of a shock-absorbing surface for cushioning a senior's fall.

Nopadon Sahachaisaeree is an associate professor in the Department of Urban and Regional Planning, Faculty of Architecture, King Mongkut's Institute of Technology Ladkrabang, Thailand. He is currently presiding over the Ph.D program in planning and Arch.D program in multidisciplinary design research. He obtains his Ph.D from University of Hawaii at Manoa under the East-West Center Scholarship. He is teaching a number of courses relevant to planning and research methodology in the doctoral level. His present research expertise involves spatial planning, urban policy, design research methodology, environment and behavioral study, design studies, and design for commercial environment. 